\title{
Ratos e homens - e 0 efeito placebo: um reencontro da cultura no caminho da natureza
}

\begin{abstract}
Stélio Marras
Lanthenas, este visionário, deu à medicina uma definição breve, mas carregada de toda uma história: "Finalmentea medicina seráo que deve ser: o conhecimento do homem natural esocial".

M ichel Foucault, 0 nascimento da clínica

O trecho, retirado de uma comédia de teatro de Eugène Durif ${ }^{1}$, traz subjacente 0 drama constante e constituinte dos laboratórios ocidentais destinados ao trabalho de invenção de medicamentos. Apenas nessa breve passagem, algo irônica, já se pode surpreender as premissas que organizam toda a prática da medicina científica e naturalista (de resto, oficial e hegemônica). Mas, vamos logo notar, premissas e práticas aí surpreendidas à montante, isto é, no seu nascedouro, lá no laboratório, onde a obra do engenho científico deve depurar entre, de um lado, o que podemos denominar de a razão da natureza, razão quimioterapêutica, razão científica; e de outro, a "má razão", qual seja senão a da cultura, fonte do efeito placebo ou sugestão. Trabalho depurativo, este, dependente do sucesso laboratorial com cobaias, sejam os ratos, sejam os "bons pacientes"; e destes, preferencialmente os "típicos" - isto é, os doentes que respondem aos testes de medicamentos de conformidade a um padrão estabelecido ou esperado, sobretudo sob parâmetro estatístico, que os circunscreve a caso clínico, e assim culminando de êxito a experimentação.

Pois do que ali sobra desta razão natural meticulosamente isolada (ou tanto quanto seja possível), eis enfim o fabrico sintético da molécula medicamentosa, já pronta para sua nova etapa (nova provação também), agora à jusante, que é a fase de sua circulação no mercado, quando, no aqui fora, espera-se que os efeitos ensaiados no laboratório se repitam. Claro, homens e ratos vão aí concebidos como Ratos, com ratos seria decididamente mais simples. A substância introduzida
apresenta nítidas reações com os ratos, grupo placebo, os prostrados, os líderes... Com ratos, sim, ratos... Com os neuróticos perguntamo-nos o que se destaca, e isso leva um tempo enorme. Será que foram escolhidos os bons pacientes? Talvez sejam muito atípicos!
\end{abstract}


contínuos no plano biofísico, assim identicamente naturais pela epistéme ocidental. Epistéme dessa cosmologia moderna que, por sua vez, informa e sustenta a lógica com que opera o pensamento das ciências médicas; essa lógica que por biologizar o homem, biologiza a doença, seja em seu diagnóstico de causas (razões de etiologia), seja em seu prognóstico prático (razões de terapêutica).

Tal o trabalho corriqueiro de depuração dos cientistas pesquisadores de laboratório, médicos, biólogos, químicos, engenheiros da natureza; o emprego científico da mais apropriada metodologia para o fito de separar e estabilizar os efeitos puramente bioquímicos na molécula medicamentosa que ali se cria; esforços e recursos concebidos e utilizados para subtrair dessa experiência laboratorial - este o ponto aqui - toda manifestação subjetiva (isto é, não controlável, não previsível, arbitrária, "atípica") que necessariamente incide quando se trata de corrigir a saúde humana.

É o caso do chamado "efeito placebo" ou "sugestão". Efeito subjetivista porque arbitrário, seja em função da psique do sujeito que idiossincraticamente o manifesta, seja em função da cultura, também sempre particular, que circunscreve os modos de sensibilidade e visão de mundo desses seus sujeitos. Efeito cujo fundamento, de princípio simbólico, mostra-se avesso ao previsível, resistente ao controle científico; pois controle, cujo fundamento, por sua vez, é biológico ou material - como o aplicado nas experiências de ação e reação com ratos de cobaia. Ora, e por ser razão pouco domesticável, compreendemos porque receba, nessa cognição naturalista, o qualificativo de "má razão" - conforme o próprio jargão nativo. Indesejável efeito, enfim, que sempre e necessariamente se manifesta à experiência (à montante ou à jusante), tal um resíduo irredutível. Resíduo que, contudo, é já o bastante para erguer todo o aparato dos laboratórios farmacológicos, definir sua função e seu destino - aliás, laboratórios não por acaso denominados "contra-placebo". E destino esse, sob todo esforço, voltado a eliminar essa tal "má razão" que insiste em se instalar na molécula medicamentosa no ato mesmo de sua criação, à montante no laboratório, tanto quanto no ato de sua ingestão, a jusante no mercado. Mas criação, finalmente, que só resiste se vencer (ou melhor, responder com índices pelo menos satisfatórios ou estáveis) o teste contra a má razão, contra a sugestão, contra-placebo.

E, contudo, não é justamente o exame dessas más razões o que permite revelar as brechas por onde escapa tudo quanto seja impossível estabilizar? De um só golpe, atingimos a regra e suas exceções - suas vicissitudes. Qual um hóspede nunca convidado, mas sempre presente, éo espectro do espírito humano que aí parece ressurgir em caminho imprevisto ${ }^{2}$. Espírito, alma ou psique, eis a expressão da cultura (que por definição, diga-se outra vez, é diversa, não universal, não repetida e assim contrária a previsões infalíveis), eis enfim a subjetividade renitente a se instalar no caminho retilíneo (ou que assim devia ser) das ciências médicas modernas. Ciências médicas que se integram às ciências físicas, as hard sciences, ciências da natureza. Claro que subitamente, sem que bem se espere, um temário caro às preocupações centrais da antropologia aí se insinua fortemente. 
Ou da etnologia - já que a sugestão aqui perseguida é a de reconhecer nos laboratórios científicos, no coração das hard sciences, o centro reprodutor e produtor da cosmologia moderna do Ocidente ${ }^{3}$ - sua diferença ontológica, portanto. Daí a pertinência de se encarar, para esta nossa etnia, as ciências naturais não como reduto impenetrável às ciências sociais, as soft sciences, cujos domínios clássicos seriam a da religião e da moral, da ética e da política, das paixões e da subjetividade, das relações sociais, da cultura. Domínio das representações. Mas haveria representações para o mundo físico da natureza? Lá, nos laboratórios físico ou químico, parece que a representação é tudo quanto deve ser afastado para apenas sobrarem não as idéias sobre a natureza (coisa própria da mentalidade primitiva, pré-lógica), mas depurar a própria natureza em si. Não como ela se representa mas como ela se apresenta. Não uma interpretação mas a verdade - a científica verdade.

Pois será precisamente por aqui que podemos compreender as razões de as ciências sociais, como a respeitar um acordo ${ }^{4}$ de cavalheiros, manterem-se quase sempre reticentes em perscrutar os fundamentos cosmológicos do pensamento científico. Mas note bem: trata-se de investigar não a sociabilidade dos cientistas (interesse de outros fins, e talvez apenas subsidiário aqui), mas a sociedade pré-arquitetada na ciência, sobretudo através dela, a replicar a cosmovisão moderna pressuposta e retroalimentada nessa produção das verdades naturais - as quais, enfim, sob a terra e o céu de uma cosmologia naturalista (tal a nossa), logo se convertem de verdades naturais a verdades sociais. Investigar, no pari passu do exame etnográfico, essa produção de enunciados, as dificuldades de suas demonstrações, a natureza de sua eficácia social. É quando, pois, o verdadeiro natural passa a verdadeiro social - e passagem onde claramente parece se alojar o que é francamente central à sensibilidade e visão de mundo moderna, o alicerce que Ihe organiza a experiência, o coração de sua epistéme, os critérios que definem os nossos julgamentos e a nossa crítica.

Certamente que a obra de Michel Foucault, sobretudo a relativa à clínica e as ciências médicas, atinge em cheio essas preocupações normalmente afastadas dos objetos sociológicos clássicos ${ }^{5}$. Das ciências à sociedade, era o "ponto de vista médico" que criava e legitimava o poder de instaurar novos e decisivos padrões de vida coletiva - o higienismo e a medicina social como exemplos mais evidentes aí. Criava, pois, necessidades. Era então a medicina científica re-coordenando tempo e espaço vis-à-vis a necessidade terapêutica, não raro urgente ${ }^{6}$. Igualmente, vemos hoje nas reflexões de Bruno Latour semelhante esforço de antropologizar a sociedade moderna”. Mas uma antropologia que ele denomina "simétrica", segundo a qual, ao que bem parece, deve de forma sistemática estender a reflexão a assuntos não apenas da política ou da "cultura" mas também a assuntos das ciências duras ou da "natureza" (donde uma antropologia das ciências), refletir especialmente sobre a constituição de ambas as esferas, sua separação (a "purificação") e sua contaminação recíproca (a "tradução") (Latour 1994). Simétrica, então, não só porque deve transportar devidamente a visada e o instrumental etnológico clássico para a investigação 
daquilo que realmente nos é central (onde estão as ciências duras, portanto), mas também porque deve recusar essa espécie de carta da "constituição moderna" (o referido acordo), segundo a qual os fatos da natureza pertenceriam ao exclusivo domínio das ciências físicas, químicas ou biológicas, enquanto os fatos da cultura pertenceriam ao domínio das ciências humanas. Para contrariar essa divisão epistemológica, é preciso considerar em sistema, outra vez Latour (2001:23), "tanto a história do envolvimento dos homens na construção dos fatos científicos quanto o envolvimento da ciência na feitura da história humana".

Assim que uma vez afastada essa epistemologia constitutiva da modernidade, não se poderá mais aceitar a separação entre Ciência e etno-conhecimento. Ora, ciência é já de partida conhecimento étnico. Ou rompemos o acordo epistemológico fundante da modernidade - esse que delimita o alcance e os objetos do conhecimento segundo a divisão entre domínios natural e social -, ou estaremos condenados a se resignar ver de longe, então sob um véu opaco e certa perplexidade etérea, isto em que afinal reside a coluna vertebral que nos sustenta o pensamento moderno. Somente assim, aliás e a propósito, é que poderemos conhecer com mais justeza nossos domínios periféricos, presentes em todo o Ocidente, como por exemplo as medicinas curandeiras, assumidamente híbridas de natureza e cultura - desde sua partida, sua carta de intenções, até suas mediações práticas e finalmente sua chegada aos resultados. Ademais, o trabalho de purificação (tal o da experimentação nos laboratórios hi-tech) explica o lugar e a função das práticas híbridas igualmente correntes. Tudo enredado em sistema, notemos que é o central que define o periférico. Se por exemplo ocorrem falhas, fracassos ou ausências no Centro, imediatamente recrudescem as alternativas do Periférico. Se a vacina não cura, ascende o recurso, exemplo a granel, aos pais de santo.

Se é assim, então a etnografia deve alargar seu campo e entrar nos laboratórios das ciências duras, locus central onde se produz e se reproduz esse enorme trabalho cosmológico de divisar natureza e cultura para os nós outros modernos ${ }^{8}$. É, por exemplo, no trabalho duro de um laboratório criador de medicamentos bio-sintéticos, ou ali especialmente, que se atualiza nossa particular (pretensamente universal) concepção de homem. Ao que parece, é desse constante trabalho que depende nossa confirmação quanto à preeminência do homem natural sobre o homem cultural - donde a origem de nossas mais acalentadas utopias, o pleno domínio da natureza (incluída portanto a natureza desse homem natural), até o sonho de se reverter os processos degenerativos do organismo ou mesmo conceber a imortalidade por meio de clonagens ou desvendamentos (da verdade natural) e manipulação dos programas genéticos. Em causa está, portanto, a manutenção do cerne do pensamento nativo moderno - por assim dizer, as crenças derivadas desse conhecimento.

Pois é o trabalho do Centro, como o da medicina oficial e hegemônica moderna, que se incumbe da perene 
cujo programa de funcionamento, estável, se repete (ou, diga-se de novo, que assim devia ser). Ocorre contudo que, vistos de perto, como lá num laboratório contra-placebo, os homens não se comportam exatamente como ratos. Seu organismo não repete exatamente o esperado. Portanto, sob escrutínio etnográfico e segundo as diretrizes já aqui expostas, a proposta agora é comentar brevemente as descrições e re-examinar as tão pertinentes conclusões de Philippe Pignarre, sociólogo e epistemólogo francês, que conduz essa visita ao laboratório "contra-placebo", lugar onde se inventa a molécula do medicamento, pilar da ciência médica do século XX.

Os pesquisadores nada precisam aprender de singular sobre os ratos enquanto ratos que vivem numa sociedade de ratos, ou sobre os camundongos enquanto camundongos que vivem numa sociedade de camundongos. É antes no sentido em que humanos e ratos têm uma história comum, são o resultado de uma evolução biológica que cruzou elementos comuns, que eles interessam aos pesquisadores. (Pignarre 1999: 73) ${ }^{10}$

Ratos e homens têm uma história comum. $\mathrm{O}$ enredo que os une reconhecemo-lo claramente como o naturalismo. Sua versão talvez irrevogável e decerto a mais difundida, bem o sabemos, foi escrita pelo inglês Charles Darwin, aí por 1860. Como ratos e homens se continuam sob o substrato da composição física, corolário de um mesmo processo evolutivo, esse tipo de compreensão que reúne o homem à natureza pelo termo da evolução biológica das espécies, e que portanto Ihes confere, nesse plano, uma ontologia comum, inferiu centralmente nos fundamentos do que se poderia denominar a cosmologia ou epistéme moderna. Ora, a experiência com ratos em laboratório, feita para aferir resultados terapêuticos para a saúde humana, assenta seus pressupostos epistemológicos nessa história comum, base do pensamento naturalista.

Mas lembremos os incômodos do personagem da comédia. Ele parece preferir os ratos - sim, os ratos aos neuróticos. E por que? Se homens e animais são equivalentes biológicos - preceito fundante dessa concepção natural de homem -, o que há então de errado com os homens? Por que não apresentam "nítidas reações" tal qual um rato? Mas que são os "bons pacientes"? Sem embargo, vamos notar que tal desencontro responde pelo fenômeno que a ciência médica reconhece como "efeito placebo", esta "má razão", e contudo irredutível no humano, que faz erguer todo o aparato do laboratório sintetizador de medicamentos e fundar a metodologia "contra-placebo". Pois seria decerto o efeito placebo a explicação que a classificação médica sentenciaria para aquele "caso" de cura da parturiente indígena (Lévi-Strauss 1975) ${ }^{11}$; ou, via de regra, para toda terapêutica que mobilize a intersubjetividade médico/doente, como por exemplo as práticas mágico-religiosas desse mesmo (mas quão semelhante?) Ocidente. Porém, se essas modalidades de tratamento (mas a medicina não tranqüilamente as reconhecerá como modalidades legítimas) já se encontram devidamente (isto é, marginalmente) classificadas na concepção hegemônica da terapêutica ocidental, não por isso a prática laboratorial descanse em terreno tão seguro.

Em tempo, será precavido aqui relembrar que a função das experiências contra-placebo em laboratório 
resume-se em discriminar a ação medicamentosa de uma molécula, objeto dessa prova, contra os efeitos psicológicos, de sugestão ou placebo. Pignarre anota que "para ser reconhecida como medicamento, uma substância, seja qual for sua origem, deve ter um resultado positivo nessa prova” (idem:17). Dessa discriminação resultam pois o remédio e sua terapêutica prescritiva. Mas como garantir e medir a eficácia dessa complicada operação depurativa? É quando nasce e se edifica o laboratório contra-placebo, com todo seus aparatos maquinários e seus recursos metodológicos, para o fito de se reduzir "ao mínimo" a colaboração do paciente no laboratório, e assim evitar a manifestação cientificamente indesejável do arbitrário volitivo:

A experimentação contra-placebo é (...) uma espécie de operação em branco, sem instruções, na qual o paciente não precisa "ajudar" o experimentador, na qual sua colaboração é reduzida ao mínimo. Se quisesse ajudar a cura, ele correria o risco de enganar o terapeuta ou de mostrar o caráter muito relativo de seu distúrbio, já que a cura é dependente ao menos em parte de sua vontade e, sendo ele, portanto, suscetível de ser curado com um placebo (que o desmascararia) (idem:46).

Contudo, laboratórios do mais alto incremento tecnológico não dispõem de outra técnica senão do "edifício comparativo" do placebo, se o objetivo é medir a qualidade e quantidade dos efeitos farmacológicos do medicamento ora em prova. Todo esforço do "dispositivo experimental inventado" resume-se, então, a "reduzir a um grau zero" este tal malquisto efeito placebo (idem:24). De fato, a prática metodológica posta em ação para os fins dessa dedução (molécula de efeito biológico - efeito placebo = medicamento) é bastante rigorosa e se quer cada vez mais sofisticada em métodos. Ocorre porém que tanto recurso disponibilizado não é ainda suficiente para garantir a decantação da pureza absoluta da química medicamentosa. O ideal cristalino da teoria (ou a integridade da epistéme que a pressupõe) segue ressentida.

O medicamento esconde dentro de si uma mistura em parte estabilizada, constituída por uma molécula ativa (biologicamente) e efeitos de sugestão, sem que se tenha os meios de discerni-los, por definição (idem:31-2).

Não importa, é preciso alcançar algum discernimento entre efeitos da molécula e efeitos de sugestão, o mínimo suficiente para tratar idênticos casos patológicos com um mesmo medicamento. Evidentemente, o pressuposto que daí devemos depreender é de que os organismos biológicos respondem analogamente seja à doença seja à terapia. Hegemônica, essa concepção naturalista permanece irrefutável na instância dos laboratórios - Ihe é um dado cosmológico. Daí a criação de diversos recursos para o teste contra-placebo: é preciso, sempre, eliminar qualquer possibilidade de reação terapêutica que não seja originária do "arrombador biológico" - este estável químico, este manipulado que deve prevalecer no composto final do medicamento em teste. 
Eliminar a subjetividade. Para tal, outro dos recursos utilizados, por exemplo, é a aplicação chamada 'em duplo-cego' da "molécula candidata a medicamento". A intenção aí consiste em negligenciar não apenas ao paciente, mas também a quem ministra o medicamento, a natureza da molécula em teste - se o que está sendo testado é já o medicamento químico ou ainda um "vazio terapêutico". Com efeito, trata-se de uma "dissimulação organizada": é necessário deliberadamente desvencilhar-se da subjetividade, dos efeitos da "sugestão" ou 'má razão'12. Se o 'duplo cego' é aplicado até para dissimular o administrador do remédio, outras técnicas metodológicas concentramse exclusivamente no paciente-teste. O recrutamento dos doentes, sem dúvida, é questão central.

Foi exatamente a constatação empírica da existência e da força da sugestão (seja a do médico sobre o paciente, seja a do patrocinador do estudo - com todas as esperanças que ele encarna - sobre o médico) que levou os experimentadores a sofisticar seus protocolos cada vez mais. Os pesquisadores inclusive aperfeiçoaram uma técnica para eliminar os pacientes altamente placebo-respondedores em estudos efetuados com um número pequeno de sujeitos. Começa-se então a realizar um estudo "placebo contra-placebo em duplo cego" para eliminar "todos os pacientes que apresentam um efeito superior a um valor-limiar fixado" (idem:25).

Daí que uma fina seleção de cobaias humanas seja feita segundo determinados critérios, como evitar os sujeitos que, já comprovadamente, respondam excessivamente ao efeito placebo, acima pois do 'valor-limiar fixado'. Não seriam esses os pacientes "atípicos" da comédia? Pois contra eles busca-se então recrutar os doentes que mais se aproximam de... ratos - isto é, aproximadamente análogos a seres que, supõe-se, sejam destituídos de reação subjetiva pronunciada. Esses, agora, os pacientes típicos. Mas entre um e outro, outra vez, não é precisamente a concepção de homem natural que define todos os critérios? É para o mesmo paciente típico, primeiro recrutado a montante no laboratório, que depois se destina o medicamento lançado a jusante, no imaginado mercado povoado dos homens naturais.

De todo modo, e a todo custo, o medicamento produzido no laboratório deve alcançar um estatuto terapêutico genérico, universal. Do contrário, ele não terá lugar no mercado farmacológico da saúde; nem seu uso não alcançará valor de troca. Então, o que também há de individual no corpo doente - mas, afinal, a doença manifesta-se sempre individualmente -, sua irredutível especificidade, ou o modo como cada doença evolui em cada organismo, tal resíduo precisa ser ou minimizado e cientificamente ignorado ou estabilizado e perfilado num só tipo, o que se intitula como caso, o conhecido caso clínico mencionado. Assim, para que o quadro patológico particular seja tratado como universal, cumpre pois recrutar doentes que se enquadrem numa 'formação gregária', os "bons pacientes" da comédia. ${ }^{13}$ Cumpre, enfim, "descontextualizar" o paciente - esta outra operação destinada a livrar o medicamento do empecilho da sugestão ${ }^{14}$-, empecilho criado por reações subjetivas pronunciadas, além portanto do 'valor-limiar fixado'. 
Pois algo será mais revelador da lógica terapêutica ocidental que a operação de "descontextualizar" seu paciente? Retirá-lo de seu contexto significa, tanto quanto seja possível (este é o ideal, ainda a despeito da prática fenomênica a jusante, sempre híbrida de natureza-cultura, de estáveis e imponderáveis), desatar-lhe os fios que o prendem ao plano social originário, a malha significante que lhe fornece sentidos para a doença que o acomete, ou sua própria história individual. No laboratório ou no consultório, cumpre neutralizar os sentidos, ou antes, destituir o paciente da função de atribuir sentidos ${ }^{15}$. Desvalorizada, pois, a alternativa lógica de o paciente recorrer a sistemas significantes contrários ao sistema naturalista em que se assenta o modelo médico-biológico, está-se automaticamente minimizando a participação subjetiva do doente. Pois não é justamente esta a estratégia dos laboratórios contra-placebo na sua faina de sintetizar o medicamento para o mercado?

Técnicas de função análoga à da "descontextualização" se acumulam. Testes em animais, em cadáveres ou em tecidos vivos tentam simular efeitos que se esperam análogos no humano. Tudo, no entanto, parece fadado a se esbarrar em limites intransponíveis. ${ }^{16}$ Pignarre adianta que o efeito placebo consiste em algo "cujo funcionamento ignoramos", e sobre o qual o modelo terapêutico moderno retém apenas um "vago conhecimento". No limite, a solução para o fabrico do medicamento científico assenta-se na verdade estatística.

Ignora-se a maneira pela qual o mecanismo da cura pela sugestão começa ou não a funcionar. Ignora-se também de que maneira mudanças corporais provocadas pela ação de uma molécula ativa sobre tecidos biológicos são capazes de interagir com esse primeiro efeito. Cada molécula é portadora de um efeito placebo próprio, cujo alcance estamos condenados a ignorar. (...) Entre cura espontânea, cura por efeito placebo e - podemos acrescentar agora - 'cura por uma ação biológica, farmacologicamente induzida', nenhum limite preciso pode ser traçado. Há um continuum suscetível de mudar a cada indivíduo, cada molécula e a cada ingestão do medicamento. É dessa incerteza essencial que vai surgir a necessidade de recorrer sempre a um dispositivo estatístico para tratar dados destinados a permanecer empíricos (Pignarre idem:27).

"Objeto bizarro", o medicamento não raro insiste em desapontar médicos e cientistas naturais. De montante a jusante, todo investimento científico e objetivo para separar níveis de estabilização derivados de seus efeitos como "arrombador biológico" sofre novos riscos, e estes ainda mais imprevistos, logo que a molécula é posta em circulação. O medicamento "transporta o efeito placebo assim como transporta moléculas, independentemente de tudo e de todos" (idem:32). Se seus efeitos puramente farmacológicos alcançam algum nível aceitável de estabilização sob exaustivos testes laboratoriais, basta que, uma vez lá fora, a molécula seja finalmente ingerida pelo doente classificatório para que, outra vez, retorne a sugestão, o placebo, a má razão da subjetividade. ${ }^{17}$

Exatamente por isso o projeto ideal de se discriminar entre o efeito do "arrombador biológico" - ele em toda sua pureza farmacológica - e o "vago" efeito de sugestão não passa, na palavra de Pignarre, de "distinção 
simples" condenada "rapidamente ao fracasso". É porque essa distinção, se é possível no plano lógico do pensamento, não o é como "exercício prático"(idem: 49). Tido como "coisa evanescente", "ângulo morto da medicina moderna", fonte de "efeitos indiscerníveis", o saber moderno atina-se embaraçado face ao efeito placebo.

(...) é o que menos dominamos, o que temos o hábito de considerar como a coisa mais evanescente, sobre a qual nenhum saber preciso é possível (idem:31).

O efeito placebo é o ângulo morto da medicina moderna, criado na experiência e ao mesmo tempo criador de efeitos indiscerníveis. Pode-se dizer que a escolha da medicina ocidental é não precisar negociar com esse tipo de efeito (idem: 148).

Quer dizer, toda dificuldade que até então parece assombrar a sintetização laboratorial dos medicamentos, ou a própria eficácia química imanente ao fármaco, diz respeito, ora veja, ao objeto das terapêuticas: o humano! Confirma Pignarre que "nenhum método permite purificar o efeito farmacológico próprio num ser humano vivo, a menos que se suprima tudo o que caracteriza um ser humano vivo"(idem:29). O problema, afinal, é que o placebo invariavelmente acompanha toda e qualquer molécula medicamentosa. De fato, seja qual for o objeto, nada é absorvido - nunca, por definição - sem antes ser simbolizado ${ }^{18}$, sem antes se imantar da volição subjetiva que, a rigor, não se submete a cálculos terapêuticos de tipo científico clássico - razão pela qual tal objeto escape dos interesses farmacológicos, médicos, mas também mercadológicos. Se o laboratório logra aferir - como de fato, em certo nível, assim se dá - algum discernimento puramente objetivo entre um e outro, ainda assim o consumo da molécula, já fora do laboratório, significa, outra vez Pignarre, um verdadeiro "salto no desconhecido" (idem: 129) ${ }^{19}$.

Ora, serão essas as razões que obscurecem a cognição médico-científica diante do fenômeno do placebo e da impossibilidade de estabilizar - prever, controlar, programar, prescrever - seus efeitos. Pois vamos aqui notar que esses são irredutivelmente singulares, variando conforme a unidade, sempre sui generis, entre o psíquico, o orgânico e o social que atravessa cada tipo individual que experimenta a quimioterapêutica. Os laboratórios contraplacebo, até pelas suas implicações mercadológicas e de funcionamento geral do sistema de saúde, não se dispõem a enfrentar tais mistérios. Tudo que lhe é objeto de conhecimento deve tomar a "forma de um arrombador biológico".

Eis o verdadeiro dilema da medicina ocidental moderna. Criou-se uma maquinaria que impede a explicação de tudo que se agrupou sob a expressão mutilante de "efeito placebo": seja remetendo-o à relação médico-doente e fazendo desaparecer sua especificidade de ser produzido pelo objeto medicamento e de não ser dissociável dele, seja remetendo-o a um resto que acompanharia a molécula, único verdadeiro objeto conhecível substancialmente quando toma a forma de um arrombador biológico (idem: 47).

Do contrário, uma terapêutica cuja "estratégia de cura" se fundamentasse no efeito placebo soaria como "seita" para a medicina objetivante: 
O médico que tentasse o impossível, isto é, constituir o efeito placebo como técnica de influência digna desse nome, correria o risco de constituir o que aprendemos a chamar de seita (idem: 48).

"Seitas" - e sob tal classificação nos deparamos, uma vez mais, com as razões de fundo que explicam as reações contrárias da medicina ortodoxa, a medicina farmacológica, para com as técnicas terapêuticas baseadas na relação intersubjetiva médico/doente. ${ }^{20} \mathrm{E}$ já aqui estará claro que para a ciência ocidental ortodoxa, a relação terapêutica assentada na intersubjetividade deve ser substituída pelo medicamento, cujo efeito há de "bastar-se a si mesmo".

A existência do objeto medicamento abala a relação entre o terapeuta e o paciente: mais nenhuma técnica de sugestão é necessária. Toda a técnica está concentrada no medicamento que deve ser suficientemente construído para bastar-se a si mesmo. A única técnica que subsiste é o modo de usar o objeto (Pignarre idem:46-7).

Tal como seja, seita ou injunção subjetiva, trata-se de uma má razão a ser extirpada da terapêutica moderna. Mas separar o efeito placebo ou, noutros termos, o dispositivo da subjetividade, daquilo que seria puramente ação farmacológica diz respeito ao âmago do nó epistemológico que insiste em barrar a realização ideal da ciência. Em que consistiria, noutros termos, tal ideal? Numa breve comparação etnológica entre alguns sistemas ameríndios de pensamento, como o dos J uruna, e o da ciência ocidental moderna, tal o nosso, Viveiros de Castro esboça o que seria este ideal - um ideal que se confunde com as próprias utopias ocidentais:

Na verdade, para o materialismo científico oficial, nós ainda somos animistas porque achamos que os seres humanos têm alma. J á não somos tão animistas quanto os índios, que acham que os animais também têm. Mas se continuarmos progredindo seremos capazes de chegar a um mundo em que não precisaremos mais dessa hipótese, sequer para os seres humanos. Tudo poderá ser descrito sob a linguagem da atitude física, e não mais da atitude intencional (Viveiros de Castro 1999).

Trata-se então, para nós, de reduzir ao máximo os níveis internos de intencionalidade - a medicina biológica decerto as classificaria como níveis não-estabilizados -, para assim concluir inteiramente o programa moderno da objetivação do mundo e dos homens. Por ora, enquanto não se o alcance (mas seria de fato possível vir a alcançála plenamente?), adota-se um "ponto de vista provisório", que ainda se baseia na decodificação de posturas subjetivas - "desejos, crenças e intenções" -, até que, um dia, tudo possa ser codificado e decodificado em "descrição puramente física":

Em suma, esse ponto de vista intencional é um ponto de vista provisório. Idealmente, seremos capazes de reduzir todos os comportamentos, todos os tipos de sistemas organizados do planeta a uma descrição puramente física. Eu atribuo desejos e intenções a você simplesmente porque é mais prático. Idealmente eu poderia ser capaz, 
deveria ser capaz - e um dia serei, a ciência será - de descrevê-lo integralmente em termos do estado de seus neurônios, que é uma descrição puramente física. Então, intenção, desejo, crença são apenas, acredite, instrumentos provisórios de descrição (idem)21.

Com efeito, era de se esperar que essa visão utópica do materialismo ocidental levada às últimas conseqüências se replicasse nas ciências médicas. Malgrado sofisticadas metodologias e "os mecanismos empregados" numa prova contra-placebo que "continuam a desafiar a análise e a compreensão", também Pignarre menciona esse horizonte norteador da medicina naturalista, em cuja base subsiste o ideal, o futuro utópico de "uma época vindoura"

em que nos prometem que não haverá mais nenhum empirismo e na qual se poderá prever o que uma molécula pode fazer num organismo humano desde sua síntese pelos químicos ou sua elaboração pelos especialistas em pesquisa genética (Pignarre idem: 18).

Subsiste enfim a "promessa naturalista", a qual, acredita-se, uma engenharia genética venha a cumprir:

Uma promessa naturalista consiste, segundo nossa definição, em projetar a invenção de terapêuticas que não mais agiriam sobre um elo intermediário das causas e dos efeitos biológicos, mas sobre o gene (embora este seja, na maioria das vezes, apenas um co-fator em numerosas enfermidades). Ela dá a entender, portanto, que o laboratório do estudo contra-placebo poderia tornar-se inútil (idem: 75-6).

Do mesmo modo, uma espécie de terapêutica cibernética dispensaria, de uma vez por todas, a relação já tão frágil e pobre, em termos de experiência intersubjetiva, entre médico e paciente.

Nesse sistema, o paciente e o médico parecem ter desaparecido, ainda que provisoriamente. A ausência de ligação, devido à maneira pela qual se socializa a molécula em medicamento, fragiliza a relação médico-doente, que nem sempre se consegue reconstruir. Essa dificuldade faz pensar que a ligação tornou-se tão frágil que poderia tendencialmente desaparecer de fato, como vemos em certos roteiros-ficções sobre a evolução da medicina, nos quais acionam-se em computadores sofisticados sistemas de identificação de sintomas e doenças. Isso já acontece em alguns sites da Internet (idem: 109)22.

Sem dúvida que o que vai aí divisado é o modo próprio como o pensamento moderno concebe e relaciona Natureza e Cultura, e a partir do qual aloca-se a ontologia do homem - claro, do homem moderno. Também, divisão em que se reconhecerá o importante suporte essencial à produção e reprodução do referido acordo moderno, a Política. É o dualismo ciência e política instaurado bem no cerne dessa cosmologia. Acordo cujo ideal infere a depuração entre Natureza e Cultura, proibida de se misturarem, sobretudo na sua instância purificadora da "constituição moderna", como assim a designou Bruno Latour: 
(...) cabe à ciência a representação dos não-humanos, mas lhe é proibida qualquer possibilidade de apelo à política; cabe à política a representação dos cidadãos, mas lhe é proibida qualquer relação com os não-humanos produzidos e mobilizados pela ciência e pela tecnologia (Latour 1994:33-4).

Ora, o pensamento moderno não percebe cultural a ciência ou a natureza (porque ciência não se contamina de representação, não é senão acesso privilegiado, metódico e objetivo à verdade absoluta e descontextualizada da Natureza - é a ordem representativa do dado), como não científica a política ou a cultura (porque aí já se está no seio das representações e das metáforas, do relativismo subjetivo dos interesses e das paixões - é a ordem representativa do construído). Como, já aqui, não reconhecer esse dualismo estrutural replicado nas oposições e contradições entre alma e corpo, subjetividade e objetividade, homens-entre-eles e coisas-em-si, humanos e nãohumanos, representação e realidade, crença e conhecimento, retórica e razão, ficção e fatos? O problema é que essa matriz dualista revela-se frágil - menos no nível da purificação do ideário moderno, que separa Natureza de Cultura, e mais no nível da tradução, em que se hibridizam Natureza e Cultura; ou sobretudo quando, ao modo antropológico, seguimos de perto as redes ${ }^{23}$, quando enfim entramos empiricamente num laboratório e acompanhamos pari passu a feitura do fato, pois a sua montante, desde a nascente da ciência dura até, enfim, surpreendermos a construção do dado.

Claro estará que essas matrizes de pares excludentes encontram-se instauradas nos fundamentos da medicina moderna - isto é, repita-se, em sua versão ortodoxa, oficial e mesmo hegemônica. O conhecimento não apenas independe da crença, mas a nega. Aquele que manipula a Natureza - seja para sintetizar o medicamento no laboratório, seja para tratar o corpo humano na clínica -, é apenas uma espécie de sujeito provisório; ele está ali como, por assim dizer, observador objetivo; e como tal, perfeitamente substituível pelo olhar igualmente treinado e objetivado do colega profissional; ele está ali como para motivar e fazer falar a voz anterior e irrefutável, pura e intocável da Natureza, a despeito das injunções políticas e subjetivas com que teve que se haver até que alcançasse o ideal depurado do dado natural.

No entanto, ainda que fossem totalmente superadas as vicissitudes que a sugestão causa aos laboratórios de produção de medicamentos, e assim finalmente já se tornassem obsoletos os métodos contra-placebo, pudemos notar que a molécula medicamentosa, uma vez fora do laboratório, irá no mercado encontrar, muito antes da absorção puramente orgânica, o sujeito e suas teias simbolizantes já plenos de crenças, desejos e intenções inclusive, ou sobretudo, a bem assentada crença naturalista (e, portanto, de natureza simbólica) nos efeitos químicos ali concentrados numa pílula. Então a problemática do residual, renitente porque irredutível, outra vez retorna, qual espectro que não se exorciza. Mas do mesmo modo com a relação médico-paciente. Por mais que, digamos, passificado seja o paciente, o caso é que ele nunca deixa de ser sujeito - nunca deixa de pensar e sentir. Ou, 
pergunte-se ao revés, como em sã consciência poderá o médico ignorar totalmente o campo relacional que, ad hoc, imediatamente se instaura entre ele e o paciente na clínica prática? Como não influenciar e não se influenciar? Como retirar daí diagnósticos e prognósticos isolados ou isentos?

Para a terapêutica moderna e sua concepção física e bioquímica, a cura deve resultar, sobretudo e idealmente, da ação das propriedades naturais das substâncias no organismo naturalizado - a ênfase, aí, reside no substrato orgânico de um ser, a todo despeito, insistentemente cultural, isto é, dotado de espírito, fonte de seus desejos, crenças e intenções - cujo controle, repita-se uma última vez, escapa da cognição científica (esta sim) típica. Para um saber que se funda na prática da causação mecânica e experimental, necessariamente descontextualizada, sempre em busca de regularidades e do controle das variáveis, o termo subjetivo deve mesmo ser afastado porque rebelde ao controle (as vicissitudes da sintetização dos medicamentos e o problema do placebo o denotam). A medicina ocidental naturalista, não será demasiado insistir, ela não deposita crença em terapêuticas de fundo simbolista, a própria atividade subjetivante, quais mecanismos inconscientes a atuar de maneira, dir-se-á, misteriosa na consecução da cura. E assim misteriosa permanecerá para essa medicina objetivante, que a todo custo busca purificar-se do efeito placebo - fonte do mistério. Curas que não se explicam pelas razões ditas objetivas passam logo a engrossar o index dos casos, precisamente, inexplicáveis. É que tal explicação demanda outra gramática, outra cognição. Mas aqui já estamos diante das restrições naturalistas que presidem nossa imaginação investigativa. Limites do conhecimento, limites epistemológicos que por ora parecem não integrar nossas mais radicais utopias. O ideário dessa medicina prevêa subtração definitiva da subjetividade, prescindência dos dispositivos simbólicos. E contudo seu resíduo é o que continua sendo o parâmetro que distingue e cria o medicamento estritamente (lembre-se: tanto quanto seja possível) biológico. A subjetividade segue obliterando a plena realização de tal ideário. Em tempo, pergunte-se: quais ciências da natureza ainda esperavam alguma advertência das ciências do homem?

Stélio M arras é cientista social, mestre em Antropologia Social pelaUSP emembro do corpo editorial da Revista Sexta-Feira - Antropologia, Artes e Humanidades. 


\section{NOTAS}

1 Via negativa, Actes Sud/Papiers, representada em 1996. O trecho da peça é citado por Pignarre (1999:63).

2 Faço aqui livre paráfrase de Claude Lévi-Strauss em seu texto "Lingüística e antropologia" (1975).

3 Moderno e ocidental são termos de acepção aproximada, freqüentemente tomados como sinônimos quando se pensa as "sociedades complexas". Certo que essa sobreposição semântica parece, em geral, não causar prejuízo relevante, mas talvez seja, aqui, virtude do rigor diferenciá-los. Assim, sugiro que Ocidente refira-se ao espaço (físico ou geográfico), ao passo que Moderno refira-se ao tempo (histórico ou social). Sem dúvida que um e outro muitas vezes supreendam-se coincidentes (Espaço/Tempo), mas a diferenciação sugerida já não os fazem idênticos. Desse modo, torna-se possível reconhecer, sob tal distinta nomenclatura, temporalidades não modernas no interior do Ocidente, assim como temporalidades modemas exteriores ao Ocidente.

4 Para a noção de "acordo moderno", ver Latour (1994) e Latour (2001).

5 Michel Foucault (1977).

6 Por exemplo, Foucault demonstrou sagazmente a afinidade entre medicina e constituição sociológica de Estado que o século XIX inaugura. O fenômeno moderno da urbanização ocidental sob os ditames da ordem capitalista exige o florescimento da medicina social. Ambas as genealogias se cruzam na homogeneidade em torno do homem normal, de tal modo que uma não mais se explicará sem a outra. "Quando [no século XIX] se falar da vida dos grupos e das sociedades, a vida da raça, ou mesmo da 'vida psicológica', não se pensará apenas na estrutura interna do ser organizado, mas na bipolaridade médica do normal e do patológico.(...) Se as ciências do homem apareceram no prolongamento das ciências da vida, é talvez porque estavam biologicamente fundadas, mas é também porque o estavam medicamente; sem dúvida por transferência, importação e, muitas vezes, metáfora, as ciências do homem utilizaram conceitos formados pelos biólogos; mas o objeto que eles se davam (o homem, suas condutas, suas realizações individuais e sociais) constituía, portanto, um campo dividido segundo o princípio do normal e do patológico" (Foucault 1994:40).

7 Foucault e Latour são, aliás, dois autores que Viveiros de Castro cuida lembrar quando se trata da antropologia das nossas sociedades. Cf. entrevista que nos concedeu à Revista Sexta Feira (1999).

8 É o que faz Bruno Latour em seu Ciência em ação: como seguir cientistas e engenheiros sociedade afora. "Nunca jamais se viu fato, teoria ou máquina que sobrevivesse fora da rede que lhe deu origem. Mais frágeis que cupins, fatos e máquinas conseguem trafegar ao longo de extensas galerias, mas não conseguem sobreviver um minuto nessa famosa e mítica 'exterioridade', o 'lá fora' tão decantado pelos filósofos da ciência." (Latour 2000:404).

9 Ou como na palavra de Foucault (1994:227): “Pode-se compreender, a partir daí, a importância da medicina para a constituição das ciências do homem: importância que não é apenas metodológica, na medida em que ela diz respeito ao ser do homem como objeto de saber positivo."

10 O assunto também foi tratado pelo autor em publicação anterior. Cf. Pignarre (1995).

11 Sob essa perspectiva aqui enunciada, cf. meu artigo “Corpo, subjetividade e cosmologia" (Marras 1999).

12 "Se se faz o estudo da molécula contra um placebo, é porque se pretende saber se a molécula prescrita pode curar por más razões, ou seja, por razões que não se devem à sua ação farmacológica-biológica própria" (Pignarre:26) ou "razões não ligadas à natureza do arrombador biológico da molécula." (idem:55).

13 “Temos aí uma peça essencial do laboratório do estudo contra-placebo: conseguir criar uma 'formação gregária', reunião de seres humanos doentes até então dispersos. Assim se forma a máquina molar que transforma pacientes individuais, doentes de maneira específica, em população agregada. A instituição militar representa o próprio paradigma da passagem do molecular ao molar com o ideal da uniformização." (idem: 43).

14 Aliás, não será por isso mesmo que podemos compreender as causas dos chamados efeitos colaterais de um medicamento? As propriedades biológicas sintetizadas e concentradas na molécula tornada medicamento abrangem um largo campo de ação no combate orgânico da doença - ação pressuposta nesse compósito biofísico universal. As técnicas de 'formação gregária' dos pacientes, 
sua "descontextualização" e a submissão do caso particular em caso clínico tipológico impelem a que o remédio aja com potência e abrangência quase sempre superiores ao demandado pela doença particular do indivíduo - ainda que esta seja uma variação de um tipo geral. Parece razoável compreender, ao menos em parte (a parte da má razão), a origem dos efeitos colaterais como advinda dessa batalha generalizada que a ação do medicamento faz disparar no interior do organismo individualizado - os antibióticos sendo, ao que parece, o exemplo mais contundente. Por isso, não raro que se cura simultaneamente em que se molesta o organismo.

15 Bem a propósito, é antes de tudo a linguagem que denota as concepções fundamentais. Pude noutra oportunidade (Marras 1999) notar que nada será mais sintomático que o doente, para nós, denomine-se paciente. Como paciente, é sujeito passivo da cura. Ou antes, o doente não aparece exatamente como um sujeito, ou não no sentido forte do termo. O sujeito definindo-se por mover ação, nossos doentes são antes passíveis da ação. Mas nem os médicos, como sujeitos, são os mais habilitados a emitir a verdade final sobre os casos, seja no diagnóstico seja no prognóstico. Este papel cabe sobretudo à tecnologia médica. À montante do processo, como num laboratório contra-placebo, vemos que o mesmo se repete. O método do "duplo-cego" o atesta veementemente. Nem ao pesquisador é franqueada a informação a respeito da natureza medicamentosa (placebo ou "arrombador biológico") da molécula em teste.

16 "As experiências mudam completamente de natureza e tornam-se incomensuráveis quando se passa de uma célula a um órgão isolado, e sobretudo de um órgão a um animal vivo e finalmente a um ser humano doente." (Pignarre idem: 125).

17 "Os efeitos [do medicamento] são diferentes segundo os indivíduos que os tomam, o que não pára de surpreender e desapontar os médicos, embora eles sejam notavelmente idênticos 'enquanto não foram tomados'". (Idem:46-7). Dessa indistinção resulta que "quanto mais se quiser levar a sério o medicamento como marcador biológico, mais difícil será dar-lhe uma definição estabilizada." (idem: 125).

18 Refiro-me à função simbólica, tal como a definiu Merleau-Ponty, fonte ilimitada de significações, criadora do "real": "porque o número e a riqueza das significações de que o homem dispõe sempre excedem o círculo de objetos definidos que mereçam o nome de significados, porque a função simbólica deve sempre estar em avanço com relação ao seu objeto e só encontra o real adiantando-o no imaginário." (Merleau-Ponty s/d: 203).

19 "Se se trata de uma prova, é porque se faz necessário organizar primeiramente o encontro terrível e desconhecido entre dois corpos, o das moléculas e o do organismo humano vivo" (idem: 32).

20 Entendo que o ferrenho debate que opõe psicanálise e psiquiatria, muito aliás sob o intuito de definir-lhes o estatuto científico, deve, em seus fundamentos, responder a esta problemática.

21 E. Viveiros de Castro, em entrevista para a revista Sexta Feira, trecho não publicado.

22 O empobrecimento da relação médico/doente deriva, antes, das conquistas da microbiologia pasteuriana ainda nos anos de 1880. Já não era mais preciso dispensar horas a fio em escuta. O historiador Alain Corbin apanha esse momento em que a "escuta torna-se uma especialidade" entre os "clínicos gerais pasteurianos": "sob pressão dos triunfos que começam a obter no combate às doenças contagiosas, eles não se dispõem mais a suportar as intermináveis narrativas dos mal-estares de seus pacientes. A escuta torna-se uma especialidade" (Corbin 1991:606). E com isso cresce enormemente a específica terapêutica psicológica a atender uma clientela cada vez maior no raiar do século XX.

23 Tal como as define, e com elas opera, Bruno Latour. Sobretudo para a definição, nos termos do autor, cf. Jamais fomos modemos (1994). Para um longo exercício de operação, tal como este autor a empreende, cf. Ciência em ação: como seguir cientistas e engenheiros sociedade afora (2000): “Nunca jamais se viu fato, teoria ou máquina que sobrevivesse fora da rede que lhe deu origem. Mais frágeis que cupins, fatos e máquinas conseguem trafegar ao longo de extensas galerias, mas não conseguem sobreviver um minuto nessa famosa e mítica 'exterioridade', o 'lá fora' tão decantado pelos filósofos da ciência” (Latour 2000:404). 


\section{REFERÊNCIAS BIBLIOGRÁFICAS:}

CORBIN, Alain. 1991. "Bastidores" In PERROT, M. [et.al.] História da vida privada, 4: da Revolução Francesa à Primeira Guerra. São Paulo: Companhia das Letras.

FOUCAULT, Michel. 1977. “Os corpos dóceis” In Vigiar e Punir - nascimento da prisão. Petrópolis: Vozes. 1994. O nascimento da clínica. Rio de J aneiro: Forense Universitária.

LATOUR, Bruno. 1994. J amais fomos modernos: ensaio de antropologia simétrica. São Paulo: Ed. 34. . 2000. Ciência em ação: como seguir cientistas e engenheiros sociedade afora. São Paulo: Editora Unesp. 2001. A esperança de Pandora: ensaios sobre a realidade dos estudos científicos. Bauru: Edusc.

LÉVI-STRAUSS, Claude. 1975. Antropologia estrutural. Rio de J aneiro: Tempo Brasileiro.

MARRAS, Stélio. 1999. “Corpo, cosmologia e subjetividade” Revista Sexta Feira (4). São Paulo: Hedra.

MERLEAU-PONTY, Maurice. s/d. "De Mauss a Claude Lévi-Strauss" In Lévi-Strauss. São Paulo: Abril Cultural. (Col. Os Pensadores).

PIGNARRE, Philippe. 1995. Les deux médecines. Médicaments, psychotropes et suggestion thérapeutique. Paris: La Découverte. . 1999. O que é o medicamento? Um objeto estranho entre ciência, mercado e sociedade. São Paulo: Ed. 34.

VIVEIROS DE CASTRO, E. 1999. “Entrevista com Eduardo Viveiros de Castro”. Revista Sexta Feira (4). São Paulo: Hedra. 
RESUMO

Sob o prisma de uma antropologia da ciência ou da modernidade, o artigo reflete sobre o fenômeno do efeito placebo, especialmente sua ocorrência nos laboratórios sintetizadores de moléculas medicamentosas. A função dos experimentos destes laboratórios, não por acaso denominados contra-placebo, é justamente a de, sob todo esforço, eliminar a ocorrência do efeito sugestão em favor do estável bioquímico. Este deve prevalecer, como um "arrombador biológico", na composição final do medicamento em teste. Trata-se de acompanhar as constantes vicissitudes por que passam tais laboratórios em sua faina para eliminar de seus pacientes experimentais manifestações da subjetividade - ou "má razão", conforme nomenclatura padrão. A proposta de fundo é reconhecer nas hard sciences, centro reprodutor da epistéme moderna e seu modo de divisar Natureza e Cultura, um imprescindível foco para a compreensão de aspectos capitais da cosmologia moderna.

\section{ABSTRACT}

Situating itself in the context of the anthropologies of science and modernity, this article discusses the placebo effect, specially its occurrence in synthesizer laboratories of medicament molecules. Such laboratories unsurprisingly know as counter-placebo -, have as their function to do every effort to eliminate the occurrence of the suggestion effect in behalf of the biochemical stable. The latter should prevail, as an "biological breaker", in the final composition of the medicament being tested. The article follows the constant inner vicissitudes that such laboratories go through in their will to eliminate from their experimental patients manifestations of the subjectivity - or "bad reason", as it is expressed by the patterned terminology. The final purpose of this study is to recognize in the hard sciences a center for the reproduction of the modern epistème as well as their mode of dividing Nature and Culture, giving us an important focus for the understanding of decisive aspects of modern cosmology. 